\title{
COMENTARIO
}

\section{Reflexiones críticas sobre el estudio de la escritura pictográfica en México*}

\author{
Arthur A. Joyce
}

C

omo ilustra la colección de artículos que integra este número especial de Desacatos, durante la última década el estudio de manuscritos pictográficos mixtecos de los periodos prehispánico y colonial temprano se ha convertido en un importante campo de estudios. Sobre la base de las obras pioneras de Alfonso Caso y la primera generación de especialistas en códices - la cual incluye a Mary Elizabeth Smith, Maarten Jansen, John Pohl, Bruce Byland y Nancy Troikehan aparecido jóvenes académicos que aportan importantes adelantos para la comprensión de la escritura pictográfica mixteca. La presente colección incluye artículos de Oudijk, Hermann, Rodríguez y Doesburg, quienes ejemplifican los aportes de esta nueva generación. Lind nos muestra cómo la investigación sobre la escritura pictográfica indígena, así como los estudios de documentos coloniales en español, amplían nuestra comprensión de la arqueología posclásica de la región mixteca. El estudio de los códices mixtecos y los documentos pictográficos del periodo colonial temprano, aunado a los trabajos sobre textos oaxaqueños antiguos (p. e., Urcid, 2001), nos proporciona una comprensión histórica que empieza a rivalizar con la que brinda la mayormente difundida y celebrada investigación sobre la epigrafía maya de las tierras bajas. Centraré el presente comentario en la metodología empleada para interpretar la escritura pictográfica mixteca. Como arqueólogo también deseo considerar las implicaciones de los avances recientes en la comprensión de la escritura mixteca para el desarrollo de un enfoque conjuntivo del pasado prehispánico que integre a la arqueología, la epigrafía, la iconografía, la etnohistoria y la etnografía.

A pesar de que Oudijk enfatiza excesivamente las diferencias entre las diversas tradiciones intelectuales que define, concuerdo en que las discusiones sobre metodología más evidentes y claras son las que ofrecen los miem-

\section{Critical Considerations in the Study of Mixtec Pictographic Writing \\ ARTHUR A. JOYCE: Universidad de Colorado, Boulder, Estados Unidos. arthur.joyce@colorado.edu \\ Traducción: Tonatiuh Soley}

\footnotetext{
* Agradezco a Manuel Hermann la invitación para participar en este número especial de Desacatos. Asimismo, agradezco a Michael Swanton y Byron Hamann sus comentarios a este artículo.
} 
bros de la escuela holandesa (p. e., Jansen, 1988; Doesburg, 2001: 29-34). Como sostiene Oudijk, el método etno-iconológico de dicha escuela implica el análisis de textos pictográficos como complejos de signos relacionados, la determinación del tema general (p. e., primordialmente religioso versus histórico) y el origen geográfico del documento, el uso de analogías para interpretar la imaginería textual, así como la evaluación de un documento tomando en cuenta su entorno histórico y político más amplio. Oudijk describe claramente cómo las analogías son fundamentales para interpretar la escritura pictográfica mixteca. El uso de fuentes etnohistóricas y etnográficas como analogías para interpretar la imaginería de los manuscritos pictográficos mixtecos se remonta al innovador trabajo de Caso, como lo muestra su uso del Mapa de Teozacualco para determinar que los códices son documentos mixtecos prehispánicos. Las fuentes de analogías incluyen documentos pictográficos coloniales con glosas en español, mixteco y otras lenguas indígenas —particularmente náhuatl—, así como textos alfabéticos de autores indígenas y españoles. Recientemente la investigación etnográfica sobre comunidades mixtecas contemporáneas ha adquirido importancia como una fuente de analogías por medio de las cuales se pueden comprender documentos prehispánicos y coloniales tempranos (p. e., Geurds, 2007; Jansen, 1982; Jansen y Pérez Jiménez, 2005, 2007; Loo, 1987; Monaghan, 1990). Estas fuentes representan un medio para proporcionar significado a los textos antiguos con base en la suposición de que existen continuidades históricas entre las prácticas e imaginerías más recientes — generalmente mejor comprendidas - y aquellas representadas en los textos pictográficos.

Los artículos que conforman la presente colección demuestran la importancia de las analogías para la interpretación de la escritura pictográfica mixteca. Por ejemplo, Sebastián van Doesburg utiliza documentos alfabéticos y mapas indígenas y españoles del periodo comprendido entre finales de los siglos XVII y XVIII, junto con estudios de geografía y topónimos modernos para deducir que el Lienzo de San Vicente el Palmar se originó en el cacicazgo de Ihualtepec, en la Mixteca Baja Occidental. La identificación del lugar de origen del lienzo permite que sea mejor contextualizado históricamente, al mostrar que representa recursos valiosos controlados por los gobernantes del cacicazgo, tales como la sal. Doesburg concluye que el documento puede haber sido hecho como parte de un acuerdo entre gobernantes durante los inicios de la Colonia. La comprensión más amplia del Lienzo de San Vicente el Palmar también permite reinterpretar otros manuscritos de principios de la Colonia en la Mixteca Baja Occidental. La aportación de Doesburg es importante porque los estudios sobre manuscritos pictográficos de la Mixteca Baja se encuentran en su infancia y su trabajo nos permite comprender aspectos importantes de la política, la economía y la geografía indígena durante los inicios de la Colonia.

El artículo de Laura Rodríguez Cano también se enfoca al estudio de la escritura pictográfica de la Mixteca Baja al abordar la lista de los 20 nombres de los días en el calendario ritual de 260 días. A pesar de que los logogramas de los 20 nombres son muy conocidos gracias a los estudios de los códices y pueden relacionarse con el calendario ritual utilizado a lo largo de Mesoamérica, la vinculación entre los logogramas y el mixteco hablado resulta más difícil. Como explica Rodríguez, el diccionario de Fray Francisco de Alvarado de 1593 incluye muy pocas palabras para los nombres de los días.

Rodríguez y otros investigadores, en vez de Alvarado, emplean documentos coloniales tempranos con glosas alfabéticas en mixteco - especialmente lienzos y mapas - como una suerte de Piedra Rosetta para determinar cómo se llamaban los nombres de los días y la relación entre el mixteco escrito y hablado. Rodríguez examina los documentos importantes de la Mixteca Baja y aporta nuevas investigaciones sobre el Lienzo de San Vicente el Palmar. Nuevamente, documentos coloniales tempranos con escritura pictográfica y alfabética proporcionan la analogía clave por medio de la cual se pueden inferir formas del lenguaje prehispánico. El presupuesto primordial necesario para justificar el uso de esta analogía - que la continuidad de los logogramas entre los periodos prehispánico tardío y colonial temprano implica una continuidad lingüística - está bien fundamentado. Sin embargo, el análisis de la autora muestra considerables variaciones en las glosas alfabéticas para los nombres particulares de 


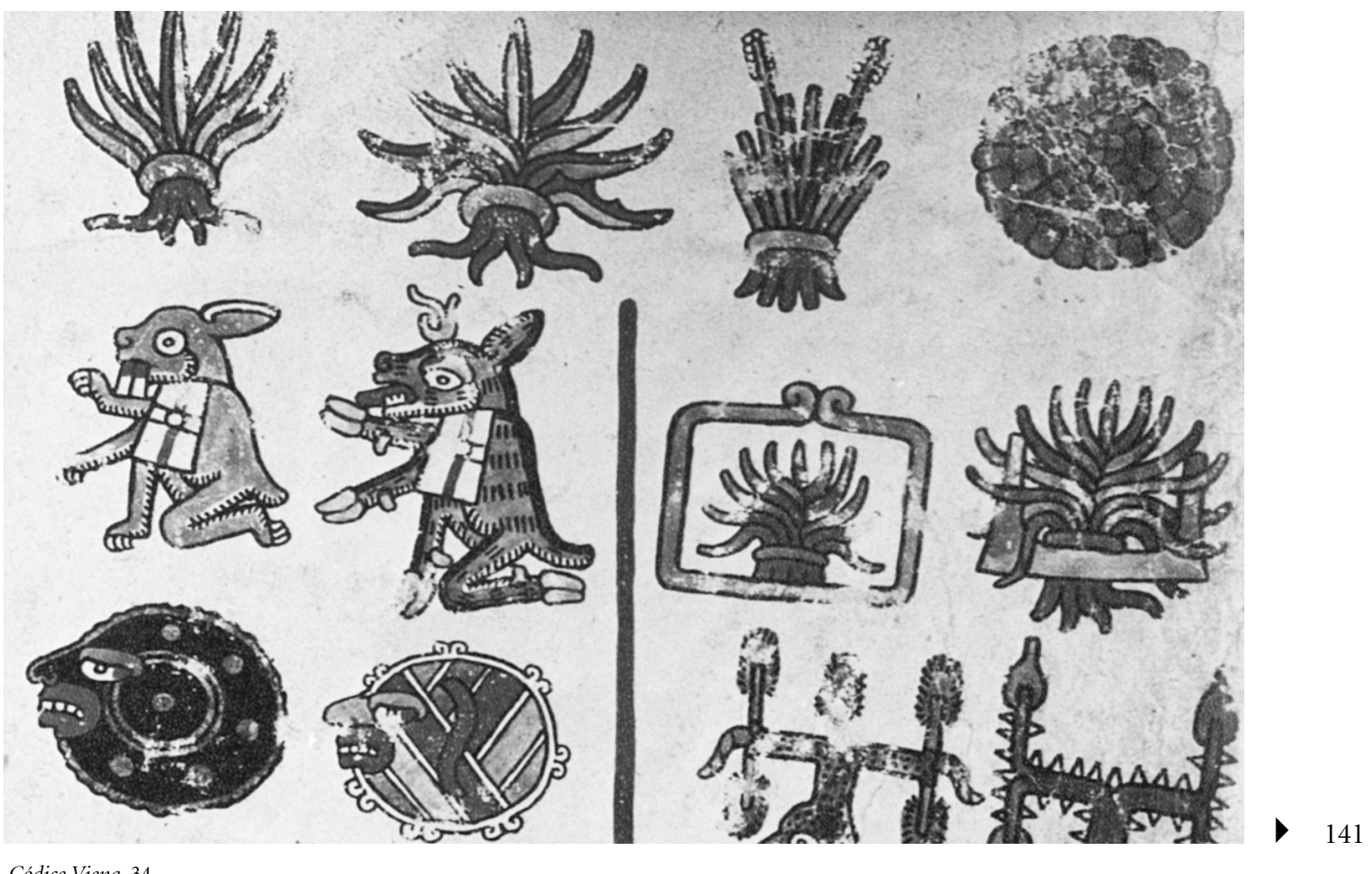

Códice Viena, 34

los días, posiblemente debido a la forma en que se registró alfabéticamente el mixteco hablado, o como resultado de la variabilidad dialectal. Su cuidadoso examen de dichas variaciones fortalece los argumentos concernientes a la forma hablada de los nombres de los días en mixteco.

De manera similar, para el estudio de los bultos sagrados en la religión mixteca prehispánica, Manuel Hermann Lejarazu emplea analogías clave extraídas de documentos coloniales. Hermann se apoya en descripciones de principios de la Colonia —en mixteco y español— de las formas, contenidos, simbolismo y usos de los bultos sagrados, junto con datos comparativos de otras partes de Mesoamérica. Su investigación ensancha el panorama de la variabilidad en la naturaleza y usos de los bultos sagrados, así como su significado más amplio en la religión mixteca.

Hermann argumenta que el bulto sagrado era una pieza central de las creencias y prácticas religiosas mixtecas (véase también Jansen, 1982: 318-325; Nowotny, 1961; Olivier, 1995; Pohl, 1994: 23-32; Stenzel, 1969). La mayoría de los investigadores se centra en los bultos sagrados como símbolos del linaje de los gobernantes y su uso en rituales para contactar antepasados y deidades por medio de ofrendas y sacrificios. Como sostiene Hermann, los bultos desempeñaban un papel importante en las ceremonias concernientes a la fundación de nuevos centros políticos, el ascenso de los gobernantes y la guerra. Sin embargo, Hermann muestra que existió una mayor diversidad de bultos sagrados de la que se reconocía con anterioridad, y que se empleaban en una variedad de ceremonias en las que participaban distintos sectores, tanto nobles como plebeyos. Por ejemplo, el autor sostiene persuasivamente que en la Mixteca las imágenes de seres divinos conocidos como $\tilde{n} u h u$, relacionadas con las representaciones de algunos bultos en los códices, son más que referentes genéricos de las propiedades sagradas de 
los bultos, como sugiere Jansen (1982: 322). Dada la variedad de bultos existente sugerida en documentos coloniales tempranos, Hermann plantea que los $\tilde{n} u h u$ caracterizaban bultos asociados con seres divinos específicos, usados en tipos particulares de rituales. Siguiendo a Pohl (1994: 29-30), sugiere que estos bultos podrían haber contenido imágenes de ñuhu de piedra o madera. Su argumento en torno a la diversidad de bultos $\tilde{n} u h u$ podría verse fortalecido mediante el cuidadoso uso de analogías basadas en el trabajo etnográfico en comunidades mixtecas contemporáneas de Monaghan (1995), quien encontró que existe una gran variedad de $\tilde{n} u h u$ asociada con una inmensa gama de características del paisaje, como los diferentes recodos y curvas de ríos, estanques y campos.

El argumento más significativo hecho por Hermann tiene que ver con el uso de bultos sagrados en rituales que no sólo se dirigen a la nobleza, sino también en ceremonias que involucran a toda la comunidad. Este argumento se basa principalmente en los registros del juicio de la inquisición en Yanhuitlán, de 1544-1546. Según los testimonios vertidos durante el proceso, tenían lugar nu- las deidades patronales de la comunidad. Dicha evidencia muestra que existían muchos tipos de bultos, que se usaban en una variedad de rituales, y que eran importantes no sólo para legitimar la autoridad del linaje gobernante, sino también para reproducir la identidad de la comunidad y la relación entre todo el pueblo y los dioses. Estos bultos eran preservados por un grupo de cuatro sacerdotes que presidía los ritos asociados con ellos y les realizaban sacrificios y ofrendas. Hermann sostiene que, entre los bultos usados para las ceremonias comunitarias, probablemente estaban los dedicados a Dzavui, dios de la lluvia, y al maíz.

No obstante, los bultos empleados en las ceremonias comunitarias nos plantean una serie de interrogantes en torno a su significado político y religioso más extenso. Hermann concluye que los bultos muestran que la religión mixteca era más compleja que lo que anteriormente se pensaba y que las personas comunes accedían a la divinidad mediante los bultos sagrados y las ceremonias relacionadas con ellos. Sin embargo, la naturaleza y el significado político de dicho acceso aún no resultan claros.
Los documentos coloniales tempranos señalan que los bultos usados en las ceremonias comunitarias eran preservados por importantes sacerdotes, lo que sugiere que los nobles actuaban como intermediarios entre el pueblo y lo divino. Ello plantea la interrogante en torno al grado en que los plebeyos podían tener acceso a las fuerzas divinas, encarnadas en los bultos, con independencia respecto a la nobleza, y hasta qué punto podían poner en duda la doctrina oficial y sus elementos ideológicos, mediante símbolos y ceremonias comunitarias. Futuros trabajos deberían tratar de averiguar las implicaciones políticas y religiosas contenidas en el importante artículo de Hermann.

Así, los artículos de Doesburg, Rodríguez y Hermann reafirman la opinión de Oudijk acerca de la importancia de la analogía en el estudio de la escritura pictográfica mixteca. Todos los artículos recopilados en este número buscan emplear múltiples fuentes de analogías para fundamentar interpretaciones particulares, lo cual fortalece el uso de inferencias. En especial, los textos de Doesburg y Rodríguez pueden verse como ejercicios de búsqueda de fuentes adicionales de analogías para comprender la escritura mixteca prehispánica. A pesar de que la interpretación de la escritura pictográfica mixteca requiere de analogías extraídas de la etnogarfía y la etnoghistoria del periodo colonial, es importante tener en mente que éstas no pueden aplicarse sin sentido crítico. Inspirándome en los planteamientos acerca del uso de analogías en la arqueología y la etnohistoria (p. e., Stahl, 1993; Wood, 1990; Wylie, 1985, 1988, 1992), deseo plantear algunas cuestiones cruciales sobre su empleo en el estudio de la escritura mixteca.

La pertinencia de las analogías particulares para realizar inferencias depende tanto de las consideraciones por parte del sujeto (source-side) como de las del lado de la fuente (subject-side) (Stahl, 1993; Wylie, 1985, 1988). Las consideraciones del lado del sujeto se refieren a la adecuación entre el fenómeno del pasado (habitualmente más distante) que intentamos comprender mejor y la analogía que elegimos usar para ampliar nuestras interpretaciones. ¿Cuáles son las similitudes y diferencias de tiempo, espacio y tema que conectan (y distinguen) a los dos fenómenos que deseamos comparar? Por ejemplo, en el estudio 
de Rodríguez hay una correspondencia estrecha entre los logogramas de los 20 nombres de días que aparecen en los documentos prehispánicos y las glosas alfabéticas en mixteco de los manuscritos coloniales tempranos usados para inferir la lengua hablada a partir de los documentos prehispánicos. Por lo tanto, entre la fuente y el sujeto de la analogía existe una concordancia cercana de los elementos visibles (los logogramas) que justifica la inferencia de similitudes en la lengua hablada.

Las consideraciones del lado de la fuente se refieren a la adecuación de las analogías que elegimos para ampliar nuestras interpretaciones. ¿Cuáles son las intenciones e inadecuaciones de las fuentes que usamos para comprender mejor el pasado? Me centraré en la evaluación de las fuentes de analogías empleadas en la interpretación de la escritura pictográfica. La justificación de una analogía particular depende de la evaluación crítica de su posibilidad de aplicación a la materia de la interpretación. La crítica de las fuentes debe considerar varios factores que pueden afectar la manera en que la analogía da forma a la interpretación (Stahl, 1993; Wylie, 1988). Como sostiene Oudijk, las disyunciones históricas resultantes del contacto con lo europeo constituyen una cuestión central al evaluar cómo los documentos coloniales y la evidencia etnográfica contribuyen a la postulación de inferencias sobre el pasado prehispánico. La mayoría de las investigaciones sobre escritura pictográfica prehispánica usa documentos indígenas y españoles del periodo colonial temprano como fuente primaria de analogías y, dada la proximidad temporal de los documentos de la época prehispánica tardía y la colonial temprana, los investigadores sienten que se justifica el enfoque histórico directo. Sin embargo, las disrupciones culturales de tan sólo las primeras décadas del periodo de contacto fueron tremendas, por lo que deben ser tomadas en cuenta al usar documentos coloniales y, especialmente, evidencia etnográfica, para plantear argumentos analógicos. Las convenciones espaciales y las influencias artísticas europeas hacen que, después del siglo XVI, disminuya la utilidad de los mapas y lienzos como fuentes de analogías. Sin embargo, incluso el uso de documentos coloniales posteriores y de otras fuentes más recientes, históricas o etnográficas, pueden brindarnos información sobre ge- nealogías de ideas y prácticas, que nos permite identificar continuidades y transformaciones. Por medio del análisis de fuentes de periodos sucesivamente anteriores, debería ser posible construir analogías temporalmente específicas. Por ejemplo, si bien la práctica de rituales sacrificiales y su significado político han cambiado radicalmente en la Mixteca desde el periodo prehispánico hasta el presente, existen continuidades que rodean el papel que desempeña el sacrificio en la definición de la relación de las personas con lo divino (Monaghan, 1990; Joyce, 2008). Por lo tanto, las analogías que parten del significado religioso del sacrificio para los habitantes contemporáneos de la Mixteca son adecuadas para inferir el sentido que tuvo dicha práctica en el pasado prehispánico, mientras que las prácticas sacrificiales del presente son menos pertinentes.

El muestreo y la ubicación de las fuentes de analogías empleadas para hacer inferencias generales sobre el pasado suponen dificultades similares a la cuestión de la relevancia temporal. ¿Los documentos provenientes de comunidades específicas de la Mixteca Baja son apropiados para formular amplias analogías sobre la región de la Mixteca en su conjunto? ¿Proyectarán las particularidades culturales y lingüísticas locales sobre áreas mucho más grandes? De igual forma, ¿ los resultados de investigaciones etnográficas hechas en unas cuantas comunidades modernas - como Nuyoo - pueden usarse para hacer generalizaciones sobre la religión prehispánica en la Mixteca, aun si se toman en cuenta las disrupciones históricas?

Otros aspectos graves que deben tenerse en cuenta al analizar críticamente las fuentes son los prejuicios de los autores de manuscritos coloniales, así como los propósitos de los documentos y el público al que se dirigen (véase Wood, 1990). Las preocupaciones en torno a los sesgos de autor se dirigen principalmente a las fuentes españolas de la Colonia, ya que reflejan los prejuicios culturales europeos ante los pueblos indígenas de América. Los escritos de académicos españoles de los siglos XVII y XVIII son menos útiles que los de autores indígenas. Las obras de cronistas e historiadores oficiales, y en particular la historia en dos volúmenes de Fray Francisco de Burgoa (1989 [1674]), con frecuencia no hacen distinciones entre las fuentes de información e intercalan cuentos y le- 


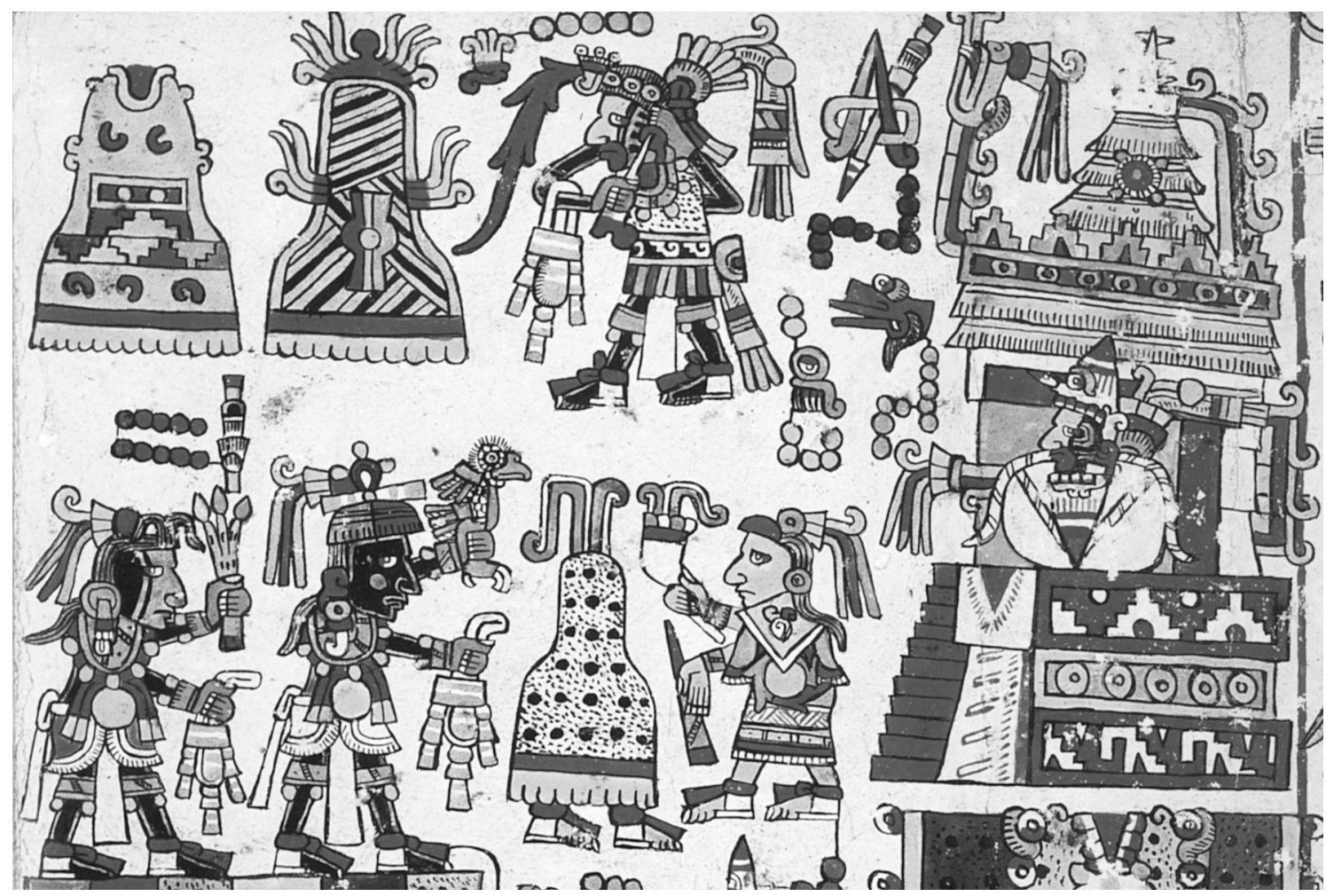

Códice Nutall, II-15.

yendas prehispánicas de Oaxaca con referencias bíblicas. Por fortuna, actualmente existe una postura más crítica frente a los documentos de autores europeos de la Colonia por parte de arqueólogos, epigrafistas y etnohistoriadores (p. e., Terraciano, 2001; Zeitlin, 2005).

Además de los sesgos etnocéntricos europeos, los académicos deben mantenerse alerta frente a los prejuicios de género y estatus presentes tanto en los documentos españoles, como en los de autoría indígena. La mayoría de los manuscritos prehispánicos y coloniales, mixtecos y españoles, fueron escritos por hombres socialmente privilegiados. Las investigaciones de género en la arqueología muestran cómo frecuentemente los prejuicios androcéntricos se reflejan al formular inferencias sobre el pasado (Wylie, 1992). Por ejemplo, a pesar de la presencia de cacicas en la Mixteca durante la Conquista, pocos arqueólogos consideran la posibilidad de que existieran mujeres prominentes en la política durante los periodos tempranos (como excepción, veáse McCafferty y McCafferty, 1994). Los estudiosos de los códices deberían considerar la posibilidad de que prejuicios de género similares se reflejen en las interpretaciones de la religión y la política prehispánica.

El estatus social probablemente constituye el sesgo más persistente en la autoría de la mayor parte de las fuentes y documentos. Tanto la escritura prehispánica como los documentos indígenas y españoles del periodo colonial fueron producidos por miembros de las élites y, habitualmente, estaban dirigidos a personas de elevada posición. Los códices consisten de manuscritos religiosos e historias de las familias gobernantes, y prácticamente no mencionan la vida de las personas comunes. De la misma manera, la información genealógica e histórica contenida en los documentos indígenas del periodo colonial temprano se centra en la nobleza, mientras que los registros españoles se dirigían principalmente a los funcionarios 
y la Corona. Aunque en algunos testimonios aparecen esclavos y gente común, como en el proceso contra la idolatría en Yanhuitlán, en los escritos del periodo colonial los plebeyos son invisibles en su mayoría. De ese modo, la inferencia de historias prehispánicas a partir de los códices, así como las fuentes de analogía usadas para la interpretación, en su mayoría, guardan silencio en torno a la vida de la gente común. Dado que los documentos prehispánicos versan sobre el linaje de los gobernantes, mientras que los coloniales con frecuencia se centran en la delimitación geográfica de las comunidades, el recuento de recursos importantes o en acuerdos legales, sus contenidos son altamente políticos y pueden ser considerados, al menos parcialmente, transcripciones públicas de las ideologías dominantes.

Si los registros documentales no nos permiten tener acceso a la perspectiva de la gente común, ¿cómo podemos entender sus relaciones con las historias, doctrina religiosa e ideología plasmadas en los manuscritos pictográficos prehispánicos? La respuesta, como sugiere Michael Lind, es que los estudiosos de la historia prehispánica de los pueblos mixtecos sean capaces de moverse a través de una multiplicidad de conjuntos de información —codicológica, etnohistórica, etnográfica, iconográfica y arqueológica - para crear un panorama más amplio de la vida, cultura e historia prehispánicas. Por ejemplo, Hermann podría considerar los contextos arqueológicos en los que fueron descubiertos los penates. Estas pequeñas figuras talladas en piedra probablemente representan bultos de momias y podrían proporcionar otra fuente de información para su estudio sobre los bultos sagrados. Otra cuestión a considerar es si la gente común aceptaba los principios ideológicos inscritos en los códices mixtecos o si existía algún grado de distanciamiento y resistencia (Joyce y Weller, 2007). En la actualidad, muy pocos estudios intentan aunar fuentes arqueológicas, etnohistóricas y codicológicas sobre el periodo posclásico tardío en la Mixteca (véanse Byland y Pohl, 1994; Forde, 2006; Joyce et al., 2004a, 2004b; Levine, 2007). Un enfoque conjuntivo como el que planteo puede usar múltiples fuentes de información complementaria, tanto para evaluar prejuicios como para llenar los vacíos de los registros del pasado. En mi propia investigación uso evi- dencias arqueológicas, etnohistóricas y epigráficas para brindar un panorama más complejo de la historia del señorío de Tututepec en la región de la Mixteca de la Costa. Por ejemplo, los códices dan cuenta de la fundación de Tututepec por el famoso gobernante 8 Venado, Garra de Jaguar, de Tilantongo, pero la arqueología nos dice que el origen de ese centro también implicó una inmigración masiva de mixtecos de la sierra, nobles y plebeyos, en una época en que las condiciones políticas de la costa eran inestables. Del mismo modo, los códices y registros coloniales tempranos nos dicen que, al momento de la conquista española, Tututepec era un reino poderoso, pero la arqueología indica que los plebeyos - y no sólo las élites - también se beneficiaron económica y socialmente del poder del centro imperial (Levine, 2007).

Como muestra la presente colección de artículos, la investigación reciente sobre los documentos pictográficos mixtecos nos brinda grandes avances para comprender la historia, cultura y lengua de esa región durante los periodos prehispánico y colonial temprano. Los trabajos que conforman este número especial de Desacatos demuestran la importancia que tiene abordar la escritura mixteca a través de una minuciosa comprensión de la cultura de esa región durante la conquista española. El uso de documentos del periodo colonial, en particular los de autoría mixteca, junto con el conocimiento etnográfico, nos proporcionan herramientas analógicas cruciales para interpretar la escritura pictográfica. Mi planteamiento es que los investigadores deben adoptar una perspectiva más crítica al justificar las analogías que usan en sus interpretaciones y que tendrían que tomar en cuenta otros registros del pasado - especialmente la arqueología- al contextualizar los textos prehispánicos.

\section{Bibliografía}

Alvarado, Francisco de, 1962 [1593], Vocabulario en lengua mixteca, hecho por los padres de la orden de predicadores, que residen en ella, y últimamente recopilado y acabado por el Padre... Vicario de Tamazulapa, de la misma orden, edición facsimilar, editada por Wigberto Jiménez Moreno, Instituto Nacional Indigenista, Instituto Nacional de Antropología e Historia, México. 
Burgoa, Fr. Francisco de, 1989 [1674], Geográfica descripción, 2 vols., Porrúa, México.

Byland, Bruce E. y John M. D. Pohl, 1994, In the Realm of 8 Deer, University of Oklahoma Press, Norman.

Doesburg, Sebastián van, 2001, Códices cuicatecos. Porfirio Díaz y Fernández Leal, Gobierno Constitucional del Estado de Oaxaca, Miguel Ángel Porrúa, México.

Forde, Jaime E., 2006, Ideology, Identity, and Icons: A Study of Mixtec Polychrome Pottery from Late Postclassic Yuca Dzaa (Tututepec), Oaxaca, Mexico, tesis de maestría, Departamento de Antropología, University of Colorado en Boulder, University Microfilms, Ann Arbor, Michigan.

Geurds, Alexander, 2007, Grounding the Past: The Praxis of Participatory Archaeology in the Mixteca Alta, Oaxaca, Mexico, CNWS Publications, Leiden.

Jansen, Maarten, 1982, Huisi Tacu. Estudio interpretativo de un libro mixteco antiguo: Codex Vindobonensis Mexicanus I, Centro de Estudios y Documentación Latinoamericanos, Ámsterdam, Países Bajos (Incidentele Publicaties, 24).

_ 1988, "The Art of Writing in Ancient Mexico: An Ethno-Iconological Perspective. Visible Religion”, Annual for Religious Iconology, núm. 6, pp. 86-113.

- y Gabina Aurora Pérez Jiménez, 2005, Codex Bodley. A Painted Chronicle from the Mixtec Highlands, Mexico, Bodleian Library, Oxford.

_ 2007, Encounter with the Plumed Serpent, University Press of Colorado, Boulder.

Joyce, Arthur A., 2008, The Main Plaza of Monte Alban: A Life History of Place. In The Archaeology of Meaningful Places, Brenda Bowser y N. Zedeno (eds.), University of Utah Press, Salt Lake City, en prensa.

_ y Errin T. Weller, 2007, "Commoner Rituals, Resistance, and the Classic-to-Postclassic Transition", Nancy Gonlin y Jon C. Lohse (eds.), Commoner Ritual and Ideology in Ancient Mesoamerica, University Press of Colorado, Boulder, pp. 141-182.

— tepec: Un centro imperial del Postclásico en la costa de Oaxaca”, en Nelly M. Robles (ed.), Estructuras politicas en el Oaxaca antiguo. Memoria de la Tercera Mesa Redonda de Monte Albán, Instituto Nacional de Antropología e Historia, México, pp. 205-230.

_- Andrew Workinger, Byron Hamann, Peter Kroefges, Maxine Oland y Stacie King, 2004b, "Lord 8 Deer 'Jaguar Claw' and the Land of the Sky. The Archaeology and History of Tututepec", Latin American Antiquity, vol. 15, núm. 3, pp. 273-297.

Levine, Marc N., 2007, Linking Household and Polity at Late Postclassic Period Yucu Dzaa (Tututepec), a Mixtec Capital on the Coast of Oaxaca, Mexico, tesis de doctorado,
Departamento de Antropología, University of Colorado en Boulder, University Microfilms, Ann Arbor, Michigan.

Loo, Peter van der, 1987, Códices, costumbres, continuidad. Un estudio de la religión mesoamericana, tesis de doctorado, University of Leiden, Leiden.

McCafferty, Sharisse D. y Geoffrey G. McCafferty, 1994, "Engendering Tomb 7 at Monte Alban: Respinning an Old Yarn”, Current Anthropology, vol. 35, núm. 2, pp. 143-166.

Monaghan, John, 1990, "Sacrifice, Death, and the Origins of Agriculture in the Codex Vienna", American Antiquity, núm. 55, pp. 559-569.

_ 1995, The Covenants with Earth and Rain, University of Oklahoma Press, Norman.

Nowotny, Karl Anton, 1961, Tlacuilolli, Ibero-amerikanische Bibliothek, Berlín.

Olivier, Guilhem, 1995, "Les Paquet sacrés ou la mémoire cachée des Indiens du Mexique central", Journal de la Société des Américanistes, núm. 81, pp. 105-142.

Pohl, John M. D., 1994, The Politics of Symbolism in the Mixtec Codices, Vanderbilt University, Nashville (Vanderbilt University Publications in Anthropology, 46).

Stahl, Ann B., 1993, "Concepts of Time and Approaches to Analogical Reasoning in Historical Perspective”, American Antiquity, vol. 58, núm. 2, pp. 235-260.

Stenzel, Werner, 1969, "Sacred Bundles in Mesoamerican Religion”, Actas del XXXVIII Congreso Internacional de Americanistas, núm. II, pp. 347-352.

Terraciano, Kevin, 2001, The Mixtecs of Colonial Oaxaca: Nudzahui History, Sixteenth through Eighteenth Centuries, Stanford University Press, Stanford.

Urcid Serrano, Javier, 2001, "Zapotec Hieroglyphic Writing”, Dumbarton Oaks Studies in Pre-Columbian Art \& Archaeology, núm. 34, Washington.

Wood, W. R., 1990, "Ethnohistory and Historical Methods", en M. B. Schiffer (ed.), Archaeological Method and Theory, vol. 2, University of Arizona Press, Tucson, pp. 81109.

Wylie, Alison, 1985, “The Reaction Against Analogy”, en Michael B. Schiffer (ed.), Advances in Archaeological Method and Theory, vol. 8, Academic Press, Orlando, pp. 63-111.

_ 1988, "'Simple Analogy and the Role of Relevance Assumptions: Implications of Archaeological Practice", International Studies in the Philosophy of Science, núm. 2, pp. 134-150.

, 1992, "The Interplay of Evidential Constraints and Political Interests. Recent Archaeological Research on Gender”, American Antiquity, vol. 57, núm. 1, pp. 15-35.

Zeitlin, Judith Francis, 2005, Cultural Politics in Colonial Tehuantepec, Stanford University Press, Stanford. 